\title{
Sağlık Maliyeti Ve Klinik Kalite İlişkisi; Prostat Kanseri Sağlık Olgusu Örneği
}

\author{
The Relationshıp of Health Cost and Clinical Quality; Prostate Cancer Case
}

Aynur TORAMAN ${ }^{1}$, Burcu ASLANTAŞ ATEŞ

\begin{abstract}
ÖZ
Sağlıkta kalite sistemi oluşumu ile gündeme alınan klinik kalite, teşhisin ve tedavinin doğruluğu ile hata oluşumlarının engellenmesi, bakım sürecinin optimizasyonu, memnuniyet artı̧s ve en iyiye ulaşma amacını gütmektedir. Verimlilik artışı ve maliyet azalışının da beraberinde geleceği düşünülen klinik kalite kapsamında 2021 Ocak ay itibariyle on bir sağlık olgusu bulunmaktadır. Bu sağlık olgularından prostat kanseri, 2019 ve 2020 klinik kalite verileri ile bu çalışmada ele alınmış; Türkiye ortalamaları ile bir durum tespiti yapılmıştır. İncelenen klinik kalite standartları kapsamındaki değerler, bazı klinik kalite göstergelerinde hedef değerin altında kaldığı tespit edilirken; bazı klinik kalite göstergelerinin de henüz klinik kalite uygulamalarının ilk yılları olmasına rağmen oldukça başarılı olunduğunu göstermektedir. Göstergelerde belirlenen hedefleri tutturma oranı arttıkça kalitenin ve dolayısıyla verimliliğin artışı, maliyetlerin azalışı mümkün olabilecektir. Klinik kalite konusunda uygulayıcıların bilinçlendirilmesi adına Covid-19 pandemisi sebebiyle sekteye uğrayan eğitim çalışmalarına ağırlık verilmesiyle birlikte planlanan hedeflere ulaşma sayısı hızla artacak ve sağlıkta kalite uygulamalarından arzu edilen sonucun alınması kolaylaştıracaktır.
\end{abstract}

Anahtar Kelimeler: Klinik Kalite, Sağlı Maliyetleri, Prostat Kanseri

\begin{abstract}
Clinical quality, which is brought to the agenda with the establishment of a quality system in health, aims to prevent the occurrence of errors with the accuracy of diagnosis and treatment, to optimize the care process, to increase satisfaction and to reach the best. There are eleven health case as of January 2021 within the scope of clinical quality. Prostate cancer, one of these health cases, was discussed in this study with 2019 and 2020 clinical quality data. Thanks to these data, the situation was tried to be determined. It has been determined that some clinical quality indicators are quite successful, although it was determined that the values within the scope of clinical quality standards remained below the target value in some clinical quality indicators. As the rate of achieving the targets determined in the indicators increases, it will be possible to increase the quality and thus productivity and decrease the costs. With the on training activities interrupted by the Covid-19 pandemic in order to raise the awareness of practitioners about clinical quality, the number of achieving the planned goals will increase rapidly and it will make it easier to get the desired result from quality practices.
\end{abstract}

Keywords: Clinical Quality, Health Costs, Prostate Cancer

\footnotetext{
${ }^{1}$ Dr. Öğr. Üyesi, Aynur TORAMAN, Sağlık Yönetimi, Süleyman Demirel Üniversitesi İiBF, aynurtoraman@sdu.edu.tr, ORCID:0000-00016180-4713

${ }^{2}$ Doç. Dr., Burcu ASLANTAŞ ATEŞ, Bankacılık ve Finans, Süleyman Demirel Üniversitesi İ̈BF, burcuates@sdu.edu.tr, ORCID: 0000-00028896-5303 


\section{GíRiş}

Türk Dil Kurumu'nda “nitelik” şeklinde ifade edilen kalite; gelir bakış açısına göre, ürün ve hizmetin müşteri ihtiyaçlarını karşılayan ve dolayısıyla müşteri memnuniyetini sağlayan özellikleri şeklinde tanımlanabilir. Maliyet bakış açısına göre ise kalite; eksikliklerin olmamasıdır. Amaca ulaşmak için, müşteri memnuniyetsizliğini gidermek için ve çeşitli hataların önlenmesi/telafi edilmesi için çalışma, çaba sarf etme anlamina gelir. ${ }^{1}$

1950'li yıllarda ilk olarak işletme içi spesifikasyonlara uygunluk şeklinde ${ }^{2}$ üretim işletmelerinde yer bulan kalite kavramı, artık birçok alanda önemli ve vazgeçilmez addedilmektedir. Hizmet sektörü ve özellikle de sağlık alanında kalite konusunda her geçen gün ilerlemeler kaydedilmektedir. ${ }^{3}$

Etkili sağlık hizmetinin unsurları arasında sayılan kalite; sağlık hizmetlerinin bilimsel standartlara ve hastaların beklentilerine uygun sunulmasinı ifade etmektedir. $\mathrm{Bu}$ noktada kaliteli sağlı hizmeti için hizmeti sunan personelin mesleki yeterliliği, hizmet sunumunun beklentilere uygunluğu ve hizmetin çeşitli kurum ve kuruluşlar tarafindan oluşturulan standartlara uyumu gereklidir. ${ }^{4}$
Sadece sağlık hizmetleri açısından değil tüm ürün ve hizmetlerde kaliteden bahsedebilmek için öncelikle standartların oluşturulması zorunludur. Türkiye' de de bu konuda Sağlık Bakanlığı tarafından çeşitli adımlar atılmakta olup, öncelikle sağlıkta dönüşüm programı kapsamına "Nitelikli ve Etkili Sağlık Hizmetleri için Kalite ve Akreditasyon" bileşeni dahil edilmiş ve 27.06.2015 tarih, 29399 sayılı "Sağlıkta Kalitenin Geliştirilmesi ve Değerlendirilmesine Dair Yönetmelik" çıkarılmıştır.

Ülkemizde sağlık hizmetlerinin kalitesinin arttırılması ve buna bağlı çalışmalara verilen önem gün geçtikçe artmaktadır. Sağlık hizmet kalitesinin ölçülmesinde karşımıza çıkan klinik kalite uygulamaları sayesinde sağlık hizmet kalitesi arttırılırken sağlık hizmet maliyetlerinin de azaltıldığı Sağlık Bakanlığı tebliğleri ve standartlarında belirtilmektedir. $\mathrm{Bu}$ bilgiler 1şı ğında klinik kalite, önemi ve üroloji dalındaki uygulamaların klinik kalite açısından ve maliyetler bağlamında değerlendirilmesi çalışmanın konusunu oluşturmaktadır.

\section{KLİNİK KALİTE}

Sağlık Bakanlığı, Sağlık Hizmetleri Genel Müdürlüğü çatısı altında sağlıkta kalite sistemi (SKS) yapısı oluşturulmuştur. Ülkemizdeki 1,2 ve 3 . Basamak kamu ve özel tüm sağlık kurum ve kuruluşlarını kapsayan Sağlikta Kalite Sisteminin amac1; ${ }^{5}$

“Türkiye'de sağllk hizmetinin etkin, etkili, verimli, zamanında ve hakkaniyet çerçevesinde sunulmasını sağlarken; hasta ve çalışan güvenliği ile hasta ve çalışan memnuniyetini en üst seviyeye çıkarmaktır." şeklinde açıklanmıştır.

$\mathrm{Bu}$ sistemin yapı taşları aşağıdaki şekilde gösterilmiştir. 


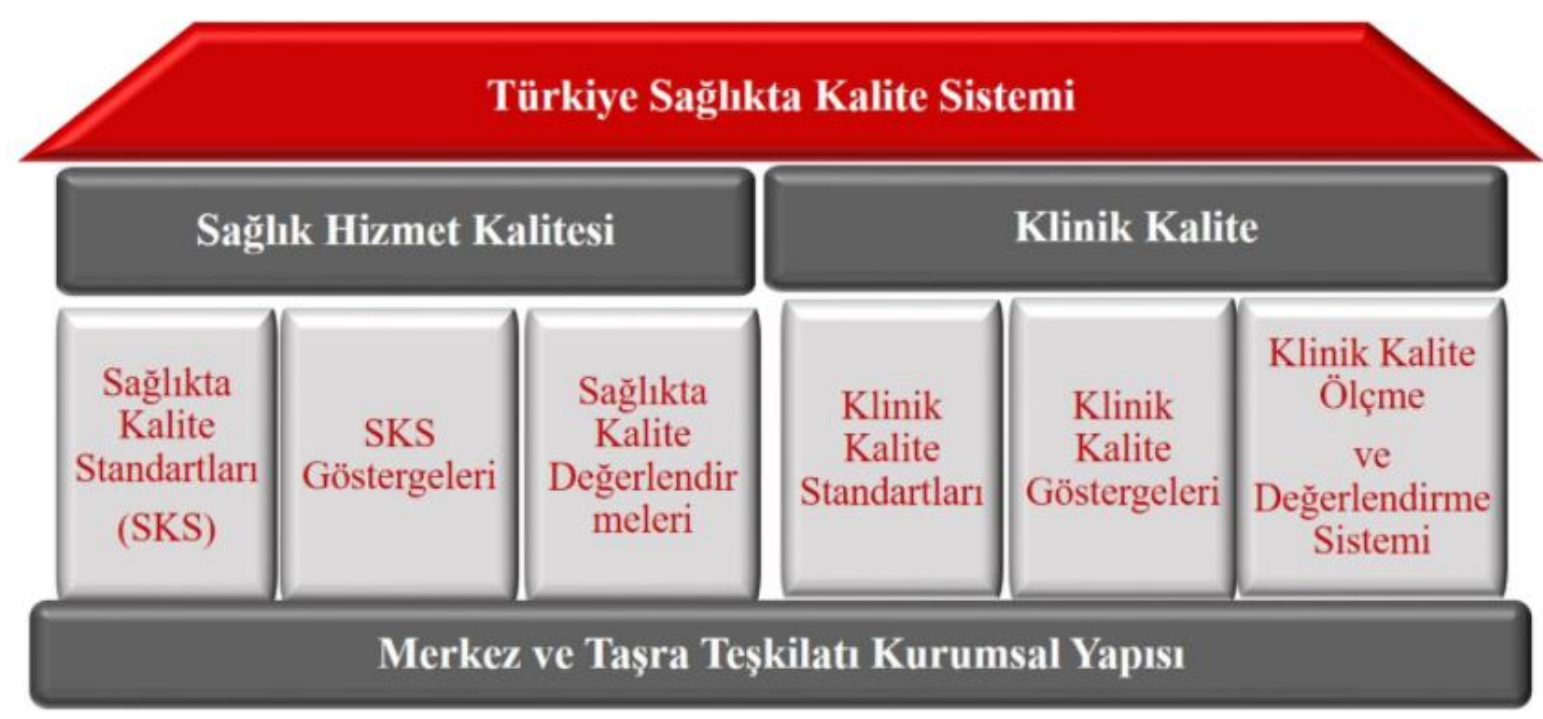

\section{Şekil 1. Türkiye Sağlıkta Kalite Sistemi}

Kaynak: Sağllk Hizmetleri Genel Müdürlüğü

(https://kalite.saglik.gov.tr/TR-8785/turkiye-saglikta-kalite-sistemi.html Erişim: 04.12.2020).

Sağlikta kalite sisteminin iki alt fonksiyonundan biri olan klinik kalite, "kanıta dayalı tıp uygulamalart ile doğru teşhis ve tedavinin sağlanmast, hataların önlenmesi, bakım sürecinin iyileştirilmesi, hasta ve çalışanların memnuniyetinin artırılması ve en iyi sağllk sonuçlarına ulaşılması" şeklinde tanımlanmaktadır. ${ }^{6} 2012$ yılında tıbbi süreçleri ve klinik sonuçları detaylı şekilde ölçmek ve izlemek hedefine yönelik çalışmalar başlatılmıştır. 2017 yılında da klinik kalite çalışmalarına dair (2017/8 sayılı genelge $)^{1}$ en temel hedeflerin, belirlenen sağlık olguları kapsamında hasta memnuniyeti ve güvenliğinin sağlanması ile birlikte en etkili sağlı çıktılarına ulaşması olduğu belirtilmektedir. $\mathrm{Bu}$ hedefe ulaşılmasında klinik çıktıların izlenmesi ve iyileştirilmesi söz konusu olmaktadır.

Klinik kalite ölçümü, klinik kalite standartları aracılığıyla hasta bakımını değerlendirmek ve iyileştirmek için kanıta dayalı olarak hazırlanan tedavi protokolleri

1 Sağlık Bakanlığı, Sağlık Hizmetleri Genel Müdürlüğü, Klinik Kalite Uygulama ve Veri Kalitesi İyileştirme Rehberi Genelgesi, 22.Mayıs 2017 tarihli 2017/8 say1l ve rehberlerini uygulamak ve 'doğru olanı yapmak' için bir yol sunmaktadır. ${ }^{7}$

Tam da bu noktada kanıta dayalı tıp uygulamalarının önemi ortaya çıkmaktadır. Kanıta dayalı tıp (KDT), hastaların tedavi sürecinde karar verirken en iyi kantların, dikkatli, açık ve akıllıca kullanılmasıdır. ${ }^{8}$

Sağlık hizmetlerinin sunumunda tıbbi hataların en aza indirilmesi, hastalara sunulan bakımın standardize edilmesi ve maliyetlerin bu çerçevede azaltılması kanıta dayalı tıp uygulamalarını popüler hale getirmiştir. Sağlık kurumlarında bakım sürecinin klinik ve ekonomik sonuçlar üzerindeki etkilerinin izlenip değerlendirilmesi kurumlara fayda sağlamaktadır. ${ }^{9}$

$\mathrm{Bu}$ bağlamda sağlıkta belirlenen öncelikli olgularla ilişkili standartlar oluşturulmakta ve yine bu olgulara yönelik ölçme ve değerlendirme için rehberler hazırlanmaktadır. Hazırlanan bu rehberlerdeki sağlık olguları, yaşam kalitesini etkileyen sağlık problemleri ve hastalık yükü göz önünde tutularak belirlenmektedir.

Klinik kalite kapsamında Mart 2021 itibariyle Diabetes Mellitus, Diz Protezi, Kalça Protezi, İnme, Koroner Kalp Hastalığı, Gebelik Süreci ve Doğum, Kolorektal 
Kanser, Kronik Obstrüktif Akciğer Hastalığı, Katarakt Cerrahisi, Prostat Kanseri, Diş İmplantı, Çocukluk Çağı Astımları, Meme Kanseri, Bariatrik ve Metabolik Cerrahi,
Hipertansiyon ve Kronik Böbrek Yetmezliği olmak üzere toplamda 19 (ondokuz) sağlık olgusu mevcuttur.

\section{KLINIIK KALITTENIN ÖNEMI}

Klinik kalite çalışmalarının temel hedefi, belirlenen sağlık olguları kapsamında hasta memnuniyeti ve güvenliğinin sağlanması ile birlikte en etkili sağlık çıktılarına ulaşmaktır. $\mathrm{Bu}$ çıktılara ulaşırken komplikasyonların ${ }^{2}$ minimize edilmesi, hasta yatış sürelerinin kısalması ve sağlık maliyetlerinin de azalması sağlanmış olacaktır. Klinik kalite ile birlikte, sağlık hizmetleri kapsamına giren uygulamaların kalitesinin ölçülmesi ve izlenmesi sağlanmaktadır. ${ }^{7}$

Klinik kalite bakım sürecinin iyileştirilmesiyle hasta bakımındaki farklılıklar azaltılmakta, erken ölümler engellenmekte, yaşam süresinin uzatılması sağlanmakta, kronik rahatsızlığı olan hastaların yaşam kalitesi arttırılmakta ve tıbbi hatalar giderek azaltılmaktadır. Tibbi hataların azaltılmasiyla da morbidite ${ }^{3}$ tedavi maliyetleri azaltılarak aynı zamanda tedavilerin daha erken sonuçlanması sağlanmaktadır ve mortaliteyi ${ }^{4}$ de azalmaktadır. Dolayısıyla tedavi daha etkin bir şekilde verilerek yaşam kalitesinde de artış da sağlanabilir. ${ }^{10}$

Sağlık Bakanlığı'nın Klinik Kalite Ölçme ve Değerlendirme Rehberlerinde klinik kalite hedefleri aşağıdaki şekilde sıralanmıştır:

- Sağlik hizmet sunumunda standart bakımın sağlanması,

2 Trbbi anlamda 'komplikasyon' terimi, bir rahatsızlığın, hastalığın veya tıbbi tedavi işleminin ön görülebilen istenmeyen etkileridir.

Komplikasyonlar bir hastalığın gidişatını kötü yönde etkiler.

3 Morbitite: Yalın olarak hastalık, hastalık hali anlamina gelmektedir.

${ }^{4}$ Mortalite: Ölüm
- Sağlık hizmet sunumunda son derece önemli olan morbidite ve mortalitenin azaltımının sağlanması,

- Komplikasyon oranlarının minimum düzeye indirilmesi,

- Yatan hasta sayısının azaltılması,

- Sağlık hizmet maliyetlerinin azaltılmasına katkı sağlanması,

- Hastaların yaşam kalitelerinin arttırılmasi,

Esasen yukarıda sayılanlar, hedef niteliğinde ancak gerçekleştiğinde tüm sağlık sistemini ciddi anlamda olumlu etkileyecek sonuç odaklı unsurlardır. Klinik kalite uygulamaları ile bu hedeflere (belirlenen olgular kapsamında) ulaşıldığında sağlık hizmetini alan kişiler sağlığına kavuşacak ve yaşam kaliteleri artacaktır. Ayrıca sağlık hizmeti sunan en üst kademede Sağlık Bakanlığ buna aracılık etmiş olacak; iş tatmini sağlanacak; verim artacaktır. $\mathrm{O}$ halde tüm bu klinik kalite hedefleri verimlilik artışı bağlamında ele alınabilir.

Verimlilik artışını amaçlayan klinik rehberler uygulandığında mikro düzeyde ilaç giderleri, ameliyat masrafları ya da tekrarlayan tedavi giderleri gibi çeşitli maliyet azalışları mümkün olmakta ve makro düzeyde hastane maliyetleri azalabilmektedir. ${ }^{11}$

Klinik kalite ile değerlendirilen sağlık hizmetinin bakım kalitesi, sağlık hizmet sunucuları, düzenleyicileri ve sağlık bakım hizmeti alıcıları tarafından giderek önem kazanmaktadır. Klinik göstergeler kullanılmadan sağlık hizmetinin kalitesinin izlenmesi ve ölçülmesi mümkün değildir. ${ }^{12}$ Sağlık hizmet sunumunda tıbbi uygulamalardaki farklılıklar maliyetleri 
etkileyen faktörlerden biridir. Örnek vermek gerekirse tanısı aynı olup, hastanede kalış süresi farklı olan hasta grubu, sezeryanla doğum oranlarındaki farklılıklar (\% 0 ile \% 40 arasında) ve diyabet bakımındaki farklılıklar sayılabilir. ${ }^{13}$ Klinik kalite sürecinin uygulanmasıyla sağlık olgularında belirli standartların izlenmesi nedeniyle, tekrarlayan tetkiklerin önüne geçilmektedir. ${ }^{14}$ Böylelikle klinik kalite gösterilerinin takibiyle, sağlik hizmetlerinin maliyet etkinliğine de katkı sağladığı ifade edilebilir.

Sağlık hizmetleri yönetiminde riskler, maliyetler ve kaynakların doğru tahsisi kalite

\section{PROSTAT KANSERI KLIINIK KALITE STANDARTLARI VE GÖSTERGELERI}

Prostat kanseri, erkeklerde hem ülkemizde hem dünyada ikinci sırada teşhis konulan kanser türüdür. $\mathrm{Bu}$ kanser türüne bağlı mortalite oranı ülkemizde yine ikinci sırada ye alırken dünya genelinde beşinci sırada yer almaktadır. Bu kanserin kesin tanısı biyopsi ile konulmaktadır. ${ }^{16}$

Prostat kanseri için hazırlanan klinik kalite rehberinde toplam 2 standart ve 7 gösterge oluşturulmuştur. Standartlar, klinik kalite açısından hastalıkların takibinde ana hedefleri göstermektedirler. Standartların uygulanma düzeyini izleyebilmek amacı ile göstergeler belirlenmiştir. Her bir gösterge için ayrı ayrı ICD- $10^{5}$ ve SUT $^{6}$ kodları mevcut olup farklı hesaplama formülleri bulunmaktadır. Ayrıca ICD-10 ve SUT kodu bulunmayan, hasta dosyalarından ya da muayene setlerinin içinden direkt alınabilen göstergeler de mevcuttur. kontrolünün önemli konularındandır. $\mathrm{Bu}$ nedenle sağllk hizmet kalitesini izlemek ve iyileştirmek için çeşitli araçlar kullanılmakta olup, klinik kalite düzeyinin belirlenmesi en popüler ve yaygın araçlardan biridir. ${ }^{15}$ Sağllk hizmetlerinde bakım süreçlerinde hataların azaltılmasıyla, hasta yatış sürelerinin kısalması, tedavi maliyetlerinin azalması, etkin tedavilerin gerçekleştirilmesi, memnuniyetlerin artması sağlanacaktır. Bunlara ek olarak hasta yaşam kalitesinde artı̧ sağlamak mümkün olabilmektedir.

\footnotetext{
${ }^{5}$ ICD 10: Uluslararası Hastalık Sınıflaması

${ }^{6}$ SUT: Sağlık Uygulama Tebliği
} 
Tablo 1. Prostat Kanseri Klinik Kalite Standartları ve Göstergeleri

\begin{tabular}{|c|c|}
\hline STANDARTLAR (S) & GÖSTERGELER (G) \\
\hline $\begin{array}{l}\text { PR.S1 } \\
\text { Prostat kanser tanısının } \\
\text { doğru konulması için } \\
\text { kanıta dayalı işlemler } \\
\text { yapılmalıdır. }\end{array}$ & $\begin{array}{l}\text { PR.G1 Alt üriner sistem şikayetleri ile gelen } 50 \text { - } 80 \text { yaş aralığındaki hastalarda PSA } \\
\text { ölçümü yapılan hasta oranı }\end{array}$ \\
\hline \multirow{5}{*}{$\begin{array}{l}\text { PR.S2 } \\
\text { Etkin cerrahi müdahalenin } \\
\text { yapılması } \\
\text { komplikasyonların } \\
\text { önlenmesi sağlanmalıdır. }\end{array}$} & $\begin{array}{l}\text { PR.G2 Total PSA değeri } 2.5 \mathrm{ng} / \mathrm{ml} \text { ve üzerinde olan } 50-60 \text { yaş aralığındaki } \\
\text { hastalarda prostat biyopsisi yappılma oranı }\end{array}$ \\
\hline & $\begin{array}{l}\text { PR.G3 Total PSA değeri } 3 \mathrm{ng} / \mathrm{ml} \text { ve üzerinde olan } 60 \text { - } 70 \text { yaş aralığındaki hastalarda } \\
\text { prostat biyopsisi yapılma oranı }\end{array}$ \\
\hline & $\begin{array}{l}\text { PR.G4 Total PSA değeri } 5 \mathrm{ng} / \mathrm{ml} \text { ve üzerinde olan } 70 \text { - } 80 \text { yaş aralığındaki hastalarda } \\
\text { prostat biyopsisi yapılma oranı }\end{array}$ \\
\hline & PR.G6 Radyoterapi alan prostat kanseri tanılı hastalarda komplikasyon görülme oranı \\
\hline & $\begin{array}{l}\text { PR.G7 Prostat kanserli hastalarda radikal prostatektomi sonrası komplikasyon } \\
\text { görülme oranı }\end{array}$ \\
\hline $\begin{array}{l}\text { PR.S3 } \\
\text { Prostat kanserinde etkin } \\
\text { takibin yapılması için } \\
\text { doğru } \\
\text { seçilmelidir. }\end{array}$ & PR.G5 Prostat kanseri tanısı alan hastalarda serbest PSA bakılma oranı \\
\hline *PR: Prostat kanseri & \\
\hline
\end{tabular}

$\mathrm{Bu}$ standartlar ve her bir standartla ilgili göstergeler, prostat kanseri teşhis ve tedavisinde önem arz etmektedir. $\mathrm{Bu}$ göstergelerin oranı prostat kanseri teşhis ve tedavisinde başarının da test edilme/edilmeme oranıdır. Her bir gösterge için bir gösterge kartı oluşturulmuş olup bu kartta ilgili göstergeyle ilişkili bilgilere yer verilmektedir. Özellikle burada dikkat edilmesi gereken hangi kodları içeren verilerin bu göstergeyle ilgili olduğu ve hangi formülle hesaplandığıdır. Ayrıca her bir gösterge kartında "hedeflenen değer" belirtilmektedir.

\section{Prostat Kanseri Standart 1}

"Prostat kanser tanısının doğru konulması için kanıta dayalı işlemler yapılmalıdır." şeklindedir. Bu standart prostat kanserinin teşhisi için önem taşımaktadır. Standart için belirlenen tek bir gösterge mevcuttur.

PR.G1 kodlu bu gösterge "alt üriner sistem şikayetleri ile gelen $50-80$ yaş aralığındaki hastalarda PSA ölçümü yapılan hasta oranı" dir.

$\mathrm{Bu}$ gösterge aşağıdaki şekilde hesaplanır ve yıllık olarak yüzde şeklinde (\%) ifade edilir:

(Paydada yer alan hasta grubunda total PSA ölçümü yapılan tekil hasta sayısı / Alt üriner sistem şikayetleri ile gelen 50 - 80 yaş aralığındaki toplam tekil erkek hasta say1s1)X100

$\mathrm{Bu}$ şekilde bulunan oranın \%95'e eşit veya ondan büyük olması gerekmektedir diğer bir ifadeyle gösterge kartı hedef değeri $\geq 95$ ile ifade edilmektedir. 


\section{Prostat Kanseri Standart 2}

$\mathrm{Bu}$ standart, "etkin cerrahi müdahalenin yapılması ve komplikasyonların önlenmesi sağlanmalıdır" şeklindedir. Cerrahi müdahalenin etkinliğinin artırılması ve işlem sırasında ve sonrasında gelişebilecek komplikasyonların (öngörülebilen istenmeyen etkiler) gelişme oranının düşürülmesi amaçlanmaktadır.

$\mathrm{Bu}$ standart beş adet göstergeyi barındırmaktadır.

PR.G2 Total PSA değeri $2.5 \mathrm{ng} / \mathrm{ml}$ ve üzerinde olan 50 - 60 yaş aralığındaki hastalarda prostat biyopsisi yapilma oranı

$\mathrm{Bu}$ gösterge aşağıdaki şekilde hesaplanır ve yıllık olarak yüzde şeklinde (\%) ifade edilir:

(Paydada yer alan hasta grubunda prostat biyopsisi yapılan tekil hasta sayıs/ Total PSA değeri $2.5 \mathrm{ng} / \mathrm{ml}$ ve üzerinde olan 50 60 Yaş arası toplam tekil hasta sayıs1)x 100

$\mathrm{Bu}$ şekilde bulunan oranın \%95'e eşit veya ondan büyük olması gerekmektedir diğer bir ifadeyle gösterge kartı hedef değeri $\geq 95$ ile ifade edilmektedir.

PR.G3 Total PSA değeri $3 \mathrm{ng} / \mathrm{ml}$ ve üzerinde olan 60 - 70 yaş aralığındaki hastalarda prostat biyopsisi yapılma oranı

$\mathrm{Bu}$ gösterge aşağıdaki şekilde hesaplanır ve yıllık olarak yüzde şeklinde (\%) ifade edilir:

(Paydada yer alan hasta grubunda prostat biyopsisi yapılan tekil hasta sayıs1/ Total PSA değeri $3 \mathrm{ng} / \mathrm{ml}$ ve üzerinde olan 60 - 70 yaş arası tekil hasta sayısı)x100

$\mathrm{Bu}$ şekilde bulunan oranın \%80'e eşit veya ondan büyük olması gerekmektedir diğer bir ifadeyle gösterge kartı hedef değeri $\geq 80$ ile ifade edilmektedir.

PR.G4 Total PSA değeri $5 \mathrm{ng} / \mathrm{ml}$ ve üzerinde olan $70-80$ yaş aralığındaki hastalarda prostat biyopsisi yapılma oranı
$\mathrm{Bu}$ göstergeyle ilgili kartta yer alan formül aşağıdaki şekildedir ve yine gösterge kartı gereği hedef değer $\geq \% 80$ dir.

(Paydada yer alan hasta grubunda prostat biyopsisi yapılan tekil hasta sayısi/ Total PSA değeri $5 \mathrm{ng} / \mathrm{ml}$ ve üzerinde olan 70-80 yaş arası tekil hasta sayısı)x100

PR.G6 Radyoterapi alan prostat kanseri tanılı hastalarda komplikasyon görülme oranı

$\mathrm{Bu}$ oran, ilgili gösterge kartına göre aşağıdaki formül ile hesaplanmalıdır. Hedef değer ise $\leq \% 30$ ' dur.

[Prostat kanser tanılı hastalarda radyoterapi sonrası komplikasyon gelişen tekil hasta sayıs1 (sistit, inkontinans, proktit) /Prostat kanseri tanısi ile radyoterapi alan toplam tekil hasta sayis1]x100

PR.G7 Prostat kanserli hastalarda radikal prostatektomi sonrası komplikasyon görülme oran1

$\mathrm{Bu}$ göstergenin oranı ise şu şekilde hesaplanır:

(Radikal prostatektomi sonrası komplikasyon gelişen tekil hasta sayıs1/ Radikal prostatektomi yapilan toplam tekil hasta say1s1)x 100

\section{Hedef değer $\leq \% 20$ ' dir.}

\section{Prostat Kanseri Standart 3}

$\mathrm{Bu}$ standart "Prostat kanserinde etkin takibin yapılması için doğru işlemler seçilmelidir." şeklindedir. Standart tek bir göstergeyi kapsamaktadır. 5 numaralı bu gösterge (PR.G5) Prostat kanseri tanısı alan hastalarda serbest PSA bakılma oranını ifade eder. İlgili gösterge kartına göre bu göstergenin hedef değeri $\leq \% 0,5$ ' dir.

Hesaplama için kullanılacak formül ise aşağıdaki şekildedir:

(Serbest PSA bakılan prostat kanser tanılı tekil hasta sayisi/Prostat Kanseri tanisi alan toplam tekil hasta say1s1)x100 


\section{MATERYAL VE METOD}

\section{Araştırmanın Amacı, Tipi ve Kapsamı}

$\mathrm{Bu}$ çalışma, sağlıkta dönüşüm programı kapsamında sağlıkta kalite çalışmalarının temel adımlarından biri olan klinik kalitenin öneminin vurgulanması amacıyla başlamış olup klinik kalite gösterge hedeflerinin gerçekleştirilmesi ile klinik maliyetin de düşürüleceği fikrinden devam etmiştir. $\mathrm{Bu}$ fikirle tasarlanan araştırma, klinik kalite gösterge hedeflerinin prostat kanseri olgusu bağlamında örneklendirilmesini ve konunun maliyet açısından önemini incelemeyi amaçlamaktadır. $\mathrm{Bu}$ amaç kapsamında çalışmaya konu hastaneden kurum izni alınmıştır.

$\mathrm{Bu}$ çalışma, klinik kalite sağlı olgularından prostat kanserini kapsayan retrospektif kayıt araştırmasıdır. Bu kapsam çerçevesinde bir hastanenin 2019 ve 2020 y1lına ait ilgili veriler alınmış; hastane, il ve Türkiye verileri karşılaştırmalı olarak incelenmiştir. $\mathrm{Bu}$ noktada belirtmek gerekir ki klinik kalite çalışmaları 2017 yılında yayımlanan bir genelge ile başlamış olsa da 2019 yilında hastanelerde verilerle desteklenerek uygulamaya geçilmiştir. Dolayısıyla elde edilen veriler klinik kalite uygulamalarının ilk verileridir. Klinik kalite ile ilgili eğitimlerin 2019 yılında daha ilk aşamalarda olması ve sonrasında Covid-19 Pandemisi nedeniyle sekteye uğraması, uygulayıcıların klinik kalite hakkında yeterince bilgiye sahip olmasını engelleyen bir unsur olarak karşımıza çıkmaktadır.

\section{Veriler}

Araştırma için elde edilen veriler her bir gösterge için önceki bölümde verilen formüller ile hesaplanan yüzdelerdir. $\mathrm{Bu}$ veriler her bir gösterge için ve ilgili kurum-ilülke açısından karşılaştırmalı olarak çalışmanın bu kısmında sunulmaktadır. Kurum olarak bahsi geçen ilgili verilerin alındığı hastanedir.

\section{BULGULAR VE TARTIŞMA}

Tablo 2. Prostat Kanseri Klinik Kalite Göstergeleri Verileri I

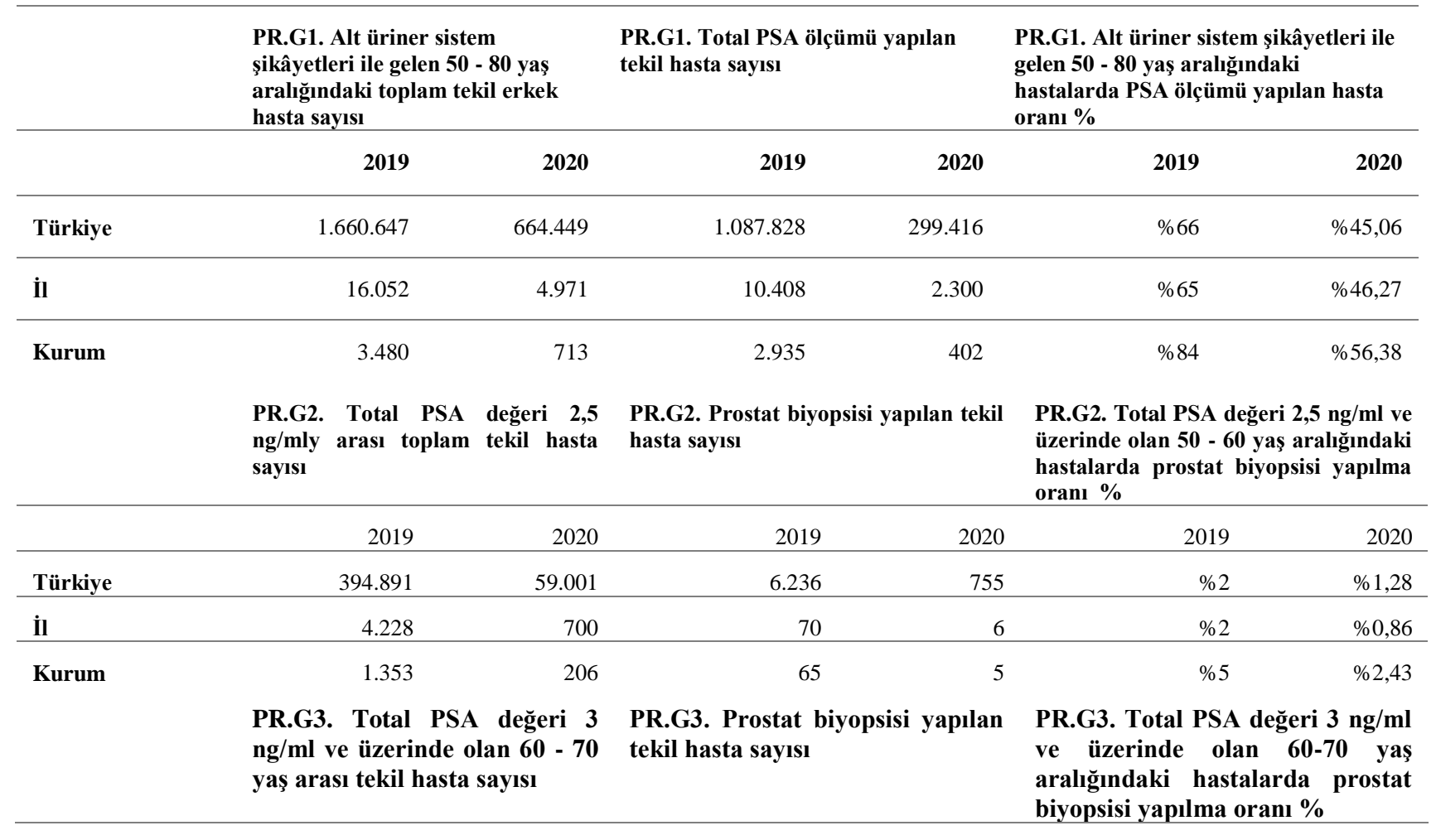




\begin{tabular}{lll}
\hline \hline GÜSBD 2021; 10(4): 597 - 609 & Gümüşhane Üniversitesi Sağlık Bilimleri Dergisi & Araştırma Makalesi \\
GUJHS 2021; 10(4): 597 - 609 & Gümüşhane University Journal of Health Sciences & Original Article \\
\hline \hline
\end{tabular}

Tablo 2. (Devamı)

\begin{tabular}{lrrrrrr}
\hline & 2019 & 2020 & 2019 & 2020 & 2019 & 2020 \\
\hline Türkiye & 435.462 & 72.298 & 12.668 & 1.743 & $\% 3$ & $\% 2,41$ \\
\hline İl & 5.535 & 994 & 130 & 10 & $\% 2$ & $\% 1,01$ \\
\hline Kurum & 1.980 & 374 & 109 & 8 & $\% 6$ & $\% 2,14$
\end{tabular}

PR.G4. Total PSA değeri 5 PR.G4. Prostat biyopsisi PR.G4. Total PSA değeri 5 ng/ml ve $\mathrm{ng} / \mathrm{ml}$ ve üzerinde olan 70-80 yapılan tekil hasta sayısı üzerinde olan 70 - 80 yaş aralığındaki yaş arası tekil hasta sayısı hastalarda prostat biyopsisi yapılma oranı \%

\begin{tabular}{lrrrrrr}
\hline & 2019 & 2020 & 2019 & 2020 & 2019 & 2020 \\
\hline Türkiye & 237.913 & 41.806 & 6.689 & 1.153 & $\% 3$ & $\% 2,76$ \\
\hline İ & 3.331 & 659 & 66 & 8 & $\% 2$ & $\% 1,21$ \\
\hline Kurum & 1.250 & 269 & 62 & 6 & $\% 5$ & $\% 2,23$ \\
\hline
\end{tabular}

Prostat kanserine ilişkin ilk klinik kalite göstergesi "PR.G1Alt üriner sistem şikâyetleri ile gelen 50 - 80 yaş aralığındaki hastalarda PSA ölçümü yapılan hasta oranı" dir. Prostat kanseri tanısinda en yaygin kullanılan test prostat spesifik antijen (PSA) dir. Sadece PSA sonucunun tek başına yeterli olmadığı ama ilk taramada mutlaka bakılması gereken bir test olduğu bilinmektedir. PSA'nın prostat kanserini tahmin etmede yetersizliği nedeniyle PSA türevleri (PSA dansitesi ve yaşa özgü PSA), PSA'nın moleküler formları (serbest PSA yüzdesi ve proPSA), PSA kinetikleri (PSA artış hızı ve ikilenme zamanı) ve prostatın görüntülenmesi ikincil destek olarak kullanılsa da bunların hiçbirinin tek başına tanıda kullanılması uygun değildir. ${ }^{16}$

2019 yılında prostat kanseri standart 1 gösterge 1 gereğince alt üriner sistem şikâyetleri ile gelen 50 - 80 yaş aralığındaki hastaların $\% 95$ ve daha fazlasına PSA ölçümü yapılması gerekmektedir. "PR.GI. Alt üriner sistem şikayetleri ile gelen 50 - 80 yaş aralığındaki hastalarda PSA ölçümü yapılan hasta oranı" göre, ilgili kurumda $\% 84$, hastanenin bulunduğu il çapında \%65 ve Türkiye genelinde ise \%66'dır. Kurumun bu göstergeye ilişkin oranının il bazında ve Türkiye ortalamasına göre oldukça iyi bir düzeyde ve beklenen orana yakın olduğu görülmektedir. 2020 yılı oranlarına bakıldığında ise hem şikâyet ile başvuran hasta sayısının hem de PSA ölçümü yapılan hasta oranının Covid-19 pandemisinin etkisiyle düşük gerçekleştiği görülmektedir.

PSA değeri, 50-60 yaş aralığında 2.5 $\mathrm{ng} / \mathrm{ml}, 60-70$ yaş aralığında $3.5 \mathrm{ng} / \mathrm{ml}$ alt sinır olarak günlük pratikte kullanılmaktadır. ${ }^{16}$ Bahsi geçen değerler üzerindeki sonuçlarda rektal muayene ve prostat biyopsi yapılmasi gerekmektedir. PR.G2 göstergesi de PSA değeri $2.5 \mathrm{ng} / \mathrm{ml}$ ve üzerinde olan 50 - 60 yaş aralığındaki hastalarda prostat biyopsisi yapilma oranını ifade etmektedir. $\mathrm{Bu}$ göstergenin oran1, "PR.G2 Total PSA değeri $2.5 \mathrm{ng} / \mathrm{ml}$ ve üzerinde olan 50 - 60 yaş aralı̆̆ındaki hastalarda prostat biyopsisi yapılma oranı" göre 2019 y1lı için kurumda \%5, hastanenin bulunduğu il çapında $\% 2$ ve Türkiye genelinde ise $\% 2$ olarak hesaplanmıştır. 2020 yılında ise bu oranlar düşmüştür.

Yukarıda bahsedildiği üzere 60-70 yaş aralığındaki hastalarda PSA değeri 3.5 $\mathrm{ng} / \mathrm{ml}$ üzerinde çıktığında klinik protokolü gereği prostat biyopsisi yapılması gerekmektedir. $\mathrm{Bu}$ oranın 2019'da gerçekleşen değerlerine "PR.G3 Total PSA değeri $3 \mathrm{ng} / \mathrm{ml}$ ve üzerinde olan 60 - 70 yaş aralığındaki hastalarda prostat biyopsisi yapılma oranı" bakıldığında kurumda yine il ve Türkiye ortalamasından yüksek $\% 6$ şeklinde gerçekleştiği, ilde \%2, Türkiye'de ise $\% 3$ olduğu görülmektedir. 2020 yılında ise yine tüm değerlerin düştüğü tespit edilmiştir. 
Prostat biyopsisinin 70-80 yaş aralığındaki hastalardan PSA değeri 5 $\mathrm{ng} / \mathrm{ml}$ 'nin üzerinde olanlara yapılma oranı ise "PR.G4 Total PSA de ğeri $5 \mathrm{ng} / \mathrm{ml}$ ve üzerinde olan 70 - 80 yaş aralığındaki hastalarda prostat biyopsisi yapılma oranı" görülmektedir. Burada da kurumun oranının il ve Türkiye ortalamasından iyi olduğu ancak yine tüm oranların pandemi dolayısıyla 2020 yılında düştüğü tespit edilmiştir.

Tablo 3. Prostat Kanseri Klinik Kalite Göstergeleri II

\begin{tabular}{|c|c|c|c|}
\hline & $\begin{array}{l}\text { PR.G5. Prostat Kanseri } \\
\text { tanısı alan toplam tekil } \\
\text { hasta sayısı }\end{array}$ & $\begin{array}{l}\text { PR.G5. Serbest PSA bakılan } \\
\text { prostat kanser tanılı tekil } \\
\text { hasta sayısı }\end{array}$ & $\begin{array}{l}\text { PR.G5. Prostat kanseri tanısı } \\
\text { alan hastalarda serbest PSA } \\
\text { bakılma oranı \% }\end{array}$ \\
\hline & 2020 & 2020 & 2020 \\
\hline Türkiye & 91.371 & 43.783 & $\% 37,68$ \\
\hline İl & 940 & 543 & $\% 38,12$ \\
\hline \multirow[t]{3}{*}{ Kurum } & 543 & 357 & $\% 66$ \\
\hline & $\begin{array}{l}\text { PR.G6. Prostat kanseri tanısı } \\
\text { ile radyoterapi alan toplam } \\
\text { tekil hasta sayısı }\end{array}$ & $\begin{array}{l}\text { PR.G6. Radyoterapi sonrası } \\
\text { komplikasyon gelişen tekil hasta } \\
\text { sayısı }\end{array}$ & $\begin{array}{l}\text { PR.G6. Radyoterapi alan prostat } \\
\begin{array}{l}\text { kanseri tanılı hastalarda } \\
\text { komplikasyon görülme oranı } \%\end{array}\end{array}$ \\
\hline & 2019 & 2019 & 2019 \\
\hline Türkiye & 8.003 & 1.354 & $\% 18,04$ \\
\hline İl & 56 & 16 & $\% 29$ \\
\hline \multirow[t]{3}{*}{ Kurum } & 54 & 15 & $\% 28$ \\
\hline & $\begin{array}{c}\text { PR.G7. Radikal } \\
\text { prostatektomi }{ }^{7} \text { yapılan toplam } \\
\text { tekil hasta sayısı }\end{array}$ & $\begin{array}{c}\text { PR.G7. Radikal Prostatektomi }{ }^{7} \\
\text { sonrası komplikasyon gelişen } \\
\text { tekil hasta sayısı }\end{array}$ & $\begin{array}{c}\text { PR.G7. Prostat kanserli } \\
\text { hastalarda radikal } \\
\text { prostatektomi }{ }^{7} \text { sonrası } \\
\text { komplikasyon görülme oranı \% }\end{array}$ \\
\hline & 2019 & 2019 & 2019 \\
\hline Türkiye & 5.258 & 1.703 & $\% 9,02$ \\
\hline İ & 74 & 34 & $\% 46$ \\
\hline Kurum & 53 & 24 & $\% 45$ \\
\hline
\end{tabular}

${ }^{7}$ Radikal Prostatektomi, prostat ve bazen gerektiğinde damarların etrafindaki lenf dokularının çıkarılması işlemidir. 
Total PSA testi, hem kanın plazma bölümünde bulunan proteinlere bağlı PSA'ları hem de serbest dolaşan PSA'ları ölçer. Serbest PSA testi ise bir proteine bağlı olmayan, kanda serbest dolaşan PSA miktarını ölçer. Her iki test de prostata dair durumları tespit etmek için kullanılır. Prostat kanseri tanısı almış hastalarda serbest PSA ölçümünün yapılması uygun görülmemektedir. Bu nedenle prostat kanseri tanısı almış kişilerde serbest PSA ölçümü yapılması kaynakların etkin kullanılmadığ ve maliyet artışına sebebiyet verdiği yönünde yorumlanabilir. Nitekim gösterge 5'in hedef değeri $\leq \% 0,5^{\prime}$ tir ve bunu doğrular niteliktedir. Oysaki Tablo 6'da görüldüğü üzere incelenen kurum, il ve Türkiye yüzdeleri prostat kanseri tanısı almış kişilere serbest PSA yapılma oranı açısından oldukça yüksek ve hedef değerin uzağındadır.

"PR.G6 Radyoterapi alan prostat
kanseri tanılı hastalarda komplikasyon
görülme oranı" göstergesi radyoterapi alan

prostat kanseri tanılı hastalarda komplikasyon görülme oranını göstermektedir. $\mathrm{Bu}$ oran için klinik kalite hedef değeri $\leq \% 30$ olarak belirlenmiştir. Buna göre kurum, il ve ülke bazında 2019 yılında hedef değerin tutturulduğu söylenebilir. 2020 y1lında radyoterapi sonras1 komplikasyon gelişen tekil hasta sayısının hem kurum hem il açısından sıfir (0) olması ise oldukça olumlu bir gelişmedir.

"PR.G7 Prostat kanserli hastalarda radikal prostatektomi sonrasi komplikasyon görülme oranı" göstergesinde de prostat kanserli hastalarda cerrahi operasyon sonrası prostat alındiktan sonra komplikasyon görülme oranları yer almaktadır. 2019 y1lında kurum, il ve Türkiye açısından hedef değer olan $\leq \% 20$ tutturulamamış olsa da 2020 yılında Türkiye genelinde hedef değer gerçekleşmiş; il ve kurum açısından ise hiçbir hastada komplikasyon görülmemesi sevindiricidir.

\section{SONUÇ VE ÖNERILLER}

Klinik kalite çalışmaları, sağlık hizmetinin kalitesinin yükseltilmesiyle yüksek kalitede sağlık bakım hizmeti sunulmasını hedeflemektedir. Klinik kalite, bakım kalitesinin ölçülmesinde kullanılan önemli bir araçtır. Türkiye'de 2017 yılında, ülke öncelikleri ve sağlık sorunlarının yaşam kalitesi üzerine etkileri göz önünde tutularak, hastalık yükü fazla olan sağlık olgularının süreç ve sonuç odaklı göstergeler ile izlenmesini hedefleyen "Türkiye Klinik Kalite Programı" başlatılmıştır. Bu kapsamda ilk etapta 11 adet sağlik olgusu izlenmeye başlanmıştır.

$\mathrm{Bu}$ sağllk olgularından biri de prostat kanseridir. Prostat kanserine ilişkin oluşturulan 7 adet gösterge bulunmakta olup, her bir göstergeye ilişkin hedef değerler Sağlık Bakanlı̆̆ 1 tarafindan belirlenmiştir. Sağlık bakım kalitesine ilişkin klinik kalite göstergeleri hangi süreçlerin iyileştirilmesi gerektiği konusunda da bilgi sağlamaktadır.
$\mathrm{Bu}$ çalışmada, bir hastanenin, bu hastanenin bulunduğu ilin ve Türkiye genelinin prostat kanserine ait 2019 ve 2020 y1lı klinik kalite verileri alınmış ve karşılaştırmalı olarak incelenmiştir. Çalışma kapsamında incelenen verilerde bazı hedef değerlere henüz ulaşılmadığı belirlenmiştir. Hedef değere ulaşılamamasının nedeninin araştırılıp, ilgili gösterge kartı için ne tür çalışmaların yapılması gerektiğine karar verilmelidir. Böylelikle sunulan bakım kalitesinde iyileştirilmeler sağlanmış olacaktır.

Klinik kalite, sağlık bakım düzeyinin belirlenmesi ve sunulan sağlık hizmetinin kalitesinin rakamsal ifadesidir. Bu bağlamda prostat kanseri sağlık olgusunda gösterge 6'daki "Radyoterapi alan prostat kanseri tanılı hastalarda komplikasyon görülme oranı" için hedef değer \%30 ve altında olarak belirlenmiş ve bu hedefin (Kurum \%28; İl \% 29; Türkiye \%17) 2019'da gerçekleştirildiği tespit edilmiştir. 2020 yılında da Türkiye 
ortalamasının \%18,04 ile hedef değere uygun olduğu; il ve kurumda ise bu oranın sifir (0) olarak gerçekleştiği yani hiçbir hastada komplikasyon görülmediği tespit edilmiştir. $\mathrm{Bu}$ veriler 1şığında klinik kalitenin hastanın bakım kalitesini arttırdığı ve sağlık maliyetlerinin azalmasına da katkı sağladığı ifade edilebilir.

Prostat kanseri sağlık olgusunda gösterge 7'deki prostat kanserli hastalarda radikal prostatektomi sonrasi komplikasyon görülme oranında da 2020 yılında hedef değerin yakalandığ 1 tespit edilmiştir. Türkiye oranı \%9,02 olarak gerçekleşirken il ve kurum oranı sıfır (0) olarak gerçekleşmiştir.

Oldukça yeni uygulamaya konan klinik kalite gösterge hedeflerine ulaşmada bu başarı memnuniyet vericidir.

Klinik kalite süreçleri sayesinde kaynak tasarrufu sağlanırken, maliyetleri azalttığ 1 ve hasta bakım kalitesini arttırdığ söylenebilir. $\mathrm{Bu}$ durum için özellikle gösterge 5'te "Prostat kanseri tanısı alan hastalarda serbest PSA bakılma oranı" örnek verilebilir. Bu gösterge için belirlenen hedef $\leq \% 0.5$ 'tir. İlgili verilerin hedef değerin çok altında olduğu görülmektedir. Kaynakların etkin kullanımı için klinik rehberler doğrultusunda hareket edilmeli ve gereksiz tahlil ve tetkikler yapılmamalı maliyetler de artırılmamalıdır.
Klinik kalite, erken tan1, tedavi ve tedavi sonrası süreçlerde en iyi sağlık sonuçlarına ulaşmayı hedeflemektedir. $\mathrm{Bu}$ kapsamda da komplikasyonları azaltmak, hasta yatışlarını azaltmak, maliyetleri azaltmak gibi hedefleri bünyesinde barındırır. $\mathrm{Bu}$ çalışmada da prostat kanseri klinik göstergeleri 1şığında klinik kalite ve sağlık maliyetleri konusuna vurgu yapılmaya çalışılmıştır.

Elde edilen sonuçlar gösteriyor ki klinik kalite kavramının henüz tam anlamıyla bilinmediği ve sağlık olgularının kapsamında bulunan sağlık çalışanları tarafından uygulamalara yansılatamadığı düşünülmektedir. Akabinde süreçlerin takibi ve iyileştirme çabalarının da bir ivme kazanması gerektiği kanısına varılmıştır. Bu noktada kurum bazında, il bazında kurulan klinik kalite komite/komisyonlarının aktif rol almaları gerekmektedir. Ek olarak belirtmek gerekir ki sağlık kurumlarında görev alan kişilerin klinik kalitenin faydalarına ve gerekliliklerine inanması son derece önem arz etmektedir. İlgili klinisyenlerin, sağlık kurumu yöneticilerin, çalışanların klinik kalite süreçlerine katılımının sağlanmasıyla sürece ilişkin başarının da beraberinde geleceğine inanılmaktadır. Son olarak klinik kalite sayesinde hastanın yaşam kalitesi arttırılırken sağlık maliyetlerinin de azalacağı çalışmanın önemli çıtıları arasında sayılabilir. 
KAYNAKLAR

1. Juran Joseph, M. (1999). How to Think about Quality In: J.M. JURAN, A.B. GODFREY, R.E. HOOGSTOEL, E.G, SCHILLING (Eds.). Quality-Control Handbook. New York: McGraw-Hill.

2. Mergen, E. (1993). “Toplam Kalite Yönetimi”, Eskişehir Anadolu Üniversitesi İktisadi ve İdari Bilimler Fak. Dergisi C, XI (1-2), 25-33.

3. Oksay, A. (2016). "Sağlık Hizmetlerinde Kalite Tam Olarak Ne Demek?" Mehmet Akif Ersoy Üniversitesi Sosyal Bilimler Enstitüsü Dergisi, 8 (14), 181-192.

4. Kısa, A. (2002). Sağlık Kurumları Yönetimi (1. Bölüm), In: N. UZKESICII (Ed.). Eskişehir: Anadolu Üniversitesi Yayınları.

5. Sağlık Bakanlığı (2020). “Türkiye Sağlıkta Kalite Sistemi”. https://shgmkalitedb.saglik.gov.tr/TR-8785/ turkiye-saglikta-kalite-sistemi.html (Erişim tarihi: 25.12.2020)

6. Gürsöz, H, Adil, M, Öztürk, A, Tarhan, D, Aksoy, H, Gündüz, Ş, Kayral İ. ve Dilmaç, E. (2017). “Türkiye Klinik Kalite Programı; Sağlık Hizmet Sunucuları, Hasta ve Hasta Yakınlarının Kalite Algısı”. Sağlıkta Performans ve Kalite Dergisi, 14(1), 73-86.

7. Avcı, K. (2017), "Sağlık Hizmet Kalitesinin İyileştirilmesi İçin Klinik Kalite Ölçümü”, Sağlık Akademisyenleri Dergisi, 4(3), 181-185.

8. Yılmaz, E. ve Çöl, M. (2014). "Kanıta Dayalı Tıp", Journal of Clinical and Analytical Medicine, 5(6), 537542 .

9. Darer, J. (2002). "Use and Evaluation of Critical
Pathways in Hospitals", Effective Clinical Practice, 5(1), 114-119.

10. Başer, D. ve Özkara, A. (2014). "Ulusal Klinik Kalite Programının Bireylerin Yaşam Kalitesi Üzerine Etkileri”. Türkiye Klinikleri J Fam Med-Special Topics, 5(3), 3447.

11. Duff, L, Kitson, A, Seers, K. and Humphris, D. (1996). "Clinicalguidelines: An Introduction to Their Development Andimplementation". Journal of Advanced Nursing, 23 (5), 887-895. (Alıntılayan Miller, M \& Kearney, N. (2004). "Guidelines for Clinical Practice: Development, Disseminationand Implementation". International Journal of Nursing Studies, 41 (2004) 813821).

12. Mainz, J. (2003). "Defining and Classifying Clinical Indicators for Quality Improvement". International Journal for Quality in Health Care, 15(6), 523-530.

13. Akalın, E. (2013). "Klinik Kalite". ANKEM Dergisi, 27 (Ek 2), 1-3.

14. Koç, E.M. ve Aksoy, H. (2019). Klinik Kalite. In: U. BEYLİK, K. AVCI (Eds.). Sağlikta Kalite Yönetim ve Akreditasyon. Ankara: Gazi Kitapevi.

15. Esposito, P. and Canton, A.D. (2014). "Clinical Audit, A Valuable Tool to İmprove Quality of Care: General Methodology and Applications in Nephrology". World J Nephrol, 3(4), 249-255.

16. Prostat Kanseri Klinik Protokolü. (2017). Sağlık Bakanlığı Sağlık Hizmetleri Genel Müdürlüğü, Sağlık Teknolojisi Değerlendirme Daire Başkanlı̆̆ı, https://klinikkalite.saglik.gov.tr/TR,25669/prostat-kanse ri-klinik-protokolu.html (Erişim tarihi: 20.12.2020). 